to infant has been suspected as occurring, particularly in the presence of intact membranes (8). The importance of this mode of transmission of infection, however, is not well understood. It may be that antepartum maternal bacteremia increases the risk to the newborn for acquiring early-onset disease and that preventing newborn early-onset sepsis is dependent on effectively treating or preventing antepartum GBS maternal bacteremia.

Previously described animal models for GBS sepsis have included inoculation of bacteria into amniotic fluid (9) and directly into newborns $(5,10,11)$ and have not included maternal infection. This animal model of vertical transmission can be used to study the mechanisms of transmission of GBS from mother to infant and to investigate regimens aimed at preventing earlyonset group B streptococcal infection.

Acknowledgments. The authors thank Harry R. Hill, M.D. for reviewing this manuscript and Doris Gutierrez for her technical assistance.

\section{REFERENCES}

1. Fischer G 1983 Summary of the National Institute of Health workshop on group B streptococcal infection. J Infect Dis 148:163-166
2. Boyer KM, Gadzala CA, Kelly PD, Burd LI, Gotoff SP 1983 Selective intrapartum chemoprophylaxis of neonatal group B streptococcal early-onset disease. II. Predictive value of prenatal cultures. J Infect Dis 148:802-809

3. Boyer KM, Gadzala CA, Kelly PD, Gotoff SP 1983 Selective intrapartum chemoprophylaxis of neonatal group B streptococcal early-onset disease. III. Interruption of mother-to-infant transmission. J Infect Dis 148:810-816

4. Yow MD, Mason EO, Leeds LJ, Thompson PK, Clark DJ, Gardner SE 1979 Ampicillin prevents intrapartum transmission of group B streptococcus. JAMA 241:1245-1247

5. Ferrieri P, Burke B, Nelson J 1980 Production of bacteremia and meningitis in infant rats with group B streptococcal serotypes. Infect Immun 27:1023 1032

6. Ancona RJ, Ferriera P 1979 Experimental vaginal colonization and motherinfant transmission of group B streptococcus in rats. Infect Immun 26:599602

7. Santos JI, Shigeoka AO, Hill HR 1982 Strain differences in virulence of group B streptococci. Pediatr Res 16:347-350

8. Bergqvist G, Holmberg G, Rydner T, Vaclavinkova V 1978 Intrauterine death due to infection with group B streptococci. Acta Obstet Gynecol Scand $57: 127-128$

9. Larsen JW, London WT, Baker CJ, Curfman BL, Sever JL 1981 Intraamniotic infection due to group B streptococcus: treatment and antibody response. Obstet Gynecol 58:222-226

10. Furtado D 1976 Experimental group B streptococcal infections in mice: hematogenous virulence and mucosal colonization. Infect Immun 13:13151320

11. Vogel LC, Kretschmer RR, Padnos DM, Kelly PD, Gotoff SP 1980 Protective value of gamma globulin preparation against group B streptococcal infections in chick embryos and mice. Pediatr Res 14:788-792

\title{
Humoral and Cell-Mediated Immunity in Growth Hormone-Deficient Children: Effect of Therapy with Human Growth Hormone
}

\author{
VAL ABBASSI AND JOSEPH A. BELLANTI \\ Division of Endocrinology, Department of Pediatrics and the International Center for Interdisciplinary Studies of \\ Immunology, Georgetown University School of Medicine, Washington, D.C. 20007
}

\begin{abstract}
To delineate the role of growth hormone (GH) in the development and function of the immune system, immunological parameters including quantitative immunoglobulins, $\mathrm{T}$ and $\mathrm{B}$ lymphocytes, phytohemagglutinin lymphoproliferative response and delayed hypersensitivity skin tests were studied in nine GH-deficient children prior to GH therapy and at 2 months and 9 to 12 months following therapy. The phytohemagglutinin response (74.1 \pm 37.6 , mean \pm SD), and the $T$ rosette $(58.3 \%$ $\pm 9.4)$, B rosette $(21.1 \% \pm 6.1)$, IgG $(810 \pm 241 \mathrm{mg} / \mathrm{dl})$, (IgA $140 \pm 85)$, and IgM (176 \pm 70) levels in GH-deficient children were comparable to age adjusted values in normal children. Following GH therapy the phytohemagglutinin response increased significantly at 9 to 12 months posttherapy, $123.2 \pm 51.9$ versus $74.1 \pm 37.6, p<0.05$. $T$ and $B$ rosettes, immunoglobulin concentrations, and hypersensitivity skin tests were not affected by GH therapy. Al-
\end{abstract}

Received June 15, 1984; accepted October 31, 1984.

Address for correspondence Val Abbassi, M.D., Department of Pediatrics, Georgetown University Hospital, 3800 Reservoir Road, N.W., Washington, D.C. 20007. though an effect of GH was not demonstrable by these studies, a positive role of GH cannot be entirely excluded since total GH deficiency did not exist in all children. (Pediatr Res 19: 299-301, 1985)

Abbreviations
GH, growth hormone
PHA, phytohemagglutinin

GH plays a significant role in the normal development of thymic-dependent immune function in lower mammals $(3,4$, $11,14)$. Although immune deficiency states in man are frequently associated with impaired growth, abnormalities of GH secretion has not been implicated in such conditions. Moreover, the precise role of $\mathrm{GH}$ in the development and maturation of the thymic-dependent and thymic-independent immune functions in humans is as yet unknown. The purpose of the study 
Table 1. PHA, T and B rosette, and immunoglobulin concentrations before and after $G H$ therapy*

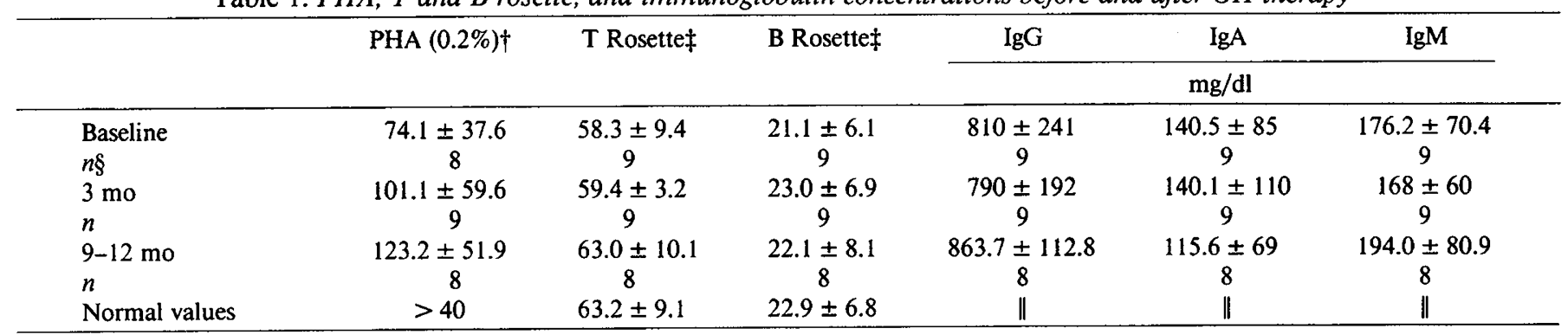

* Data are presented as mean $\pm \mathrm{SD}$.

$\dagger 0.2 \%$, concentration of PHA employed in the assay. Results are expressed as stimulation index, the ratio of cpm $\left(\left[{ }^{3} \mathrm{H}\right]\right.$ thymidine uptake) of stimulated lymphocytes over cpm of unstimulated control lymphocytes.

$\ddagger \%$ of lymphocytes forming rosette per 100 lymphocytes.

$\S$ No. of samples for each group.

|| See Reference 15 for normal age adjusted values.

was to investigate the immunological responses of children with GH deficiency, before and after GH therapy.

\section{SUBJECTS}

Nine children 3-15 yr of age with GH deficiency were investigated. The diagnosis of $\mathrm{GH}$ deficiency was based on clinical and biochemical findings. All children were more than $3 \mathrm{SD}$ below the mean height for age, and their growth velocities were $4 \mathrm{~cm} / \mathrm{yr}$ or less. Skeletal maturation was delayed by more than $2 \mathrm{yr}$ in all cases. At least two stimuli of GH secretion (L-dopa, arginine, insulin-induced hypoglycemia, glucagon) were used to assess pituitary growth hormone responsiveness. In all children, the maximum $\mathrm{GH}$ response was less than $5 \mathrm{ng} / \mathrm{ml}$ following provocation. In addition to $\mathrm{GH}$ concentrations, serum T4, thyroid-stimulating hormone, cortisol, $\mathrm{Ca}, \mathrm{P}$, alkaline phosphatase, blood urea nitrogen, creatinine, liver enzymes, bilirubin, total protein, $\mathrm{A} / \mathrm{G}$ ratio, triglycerides, and cholesterol were determined in all children. These studies all were found to be within normal limits except for the T4 and cortisol levels in one patient who suffered from congenital panhypopituitarism. He was given T4 replacement therapy, but cortisol replacement was withheld because ACTH deficiency was incomplete. The onset of growth deceleration occurred in the first $2 \mathrm{yr}$ of life in five children and beyond age 5 in four children. The interval between presumed onset of GH deficiency and the time of study ranged from 3 to $10 \mathrm{yr}$.

\section{METHODS}

Prior to initiation of GH therapy the following baseline studies were conducted. Humoral immunity was evaluated by quantitation of B lymphocytes by the EAC method (9); immunoglobulins were quantified by radioimmunodiffusion (7). Cell-mediated immunity was assessed by quantitation of $T$ lymphocytes by the $\mathrm{E}$ rosette technique (16), by assessing the PHA lymphoproliferative response (10), and by delayed hypersensitivity skin tests (mumps, SK-SD, PPD, and candida). The studies were repeated at 3 months and at 9-12 months following GH therapy. GH was measured by radioimmunoassay by methods previously described (12). GH for treatment of the children was provided by the National Hormone and Pituitary Program. A dose of 0.1 $\mathrm{U} / \mathrm{kg}$ body weight was injected three times weekly on an alternate day basis. The effectiveness of GH therapy was demonstrated by a significant increase in linear growth ranging from $6-10 \mathrm{~cm} / \mathrm{yr}$ in each child. One child developed $\mathrm{GH}$ antibodies after 12 months of therapy with subsequent diminution of her growth response. Informed and written consent was obtained from parents and children when applicable.

\section{RESULTS}

Baseline immunological studies and results following GH therapy are shown in Table 1. The PHA response $74.1 \pm 37.6$ (mean \pm SD), and the T rosette $58.3 \% \pm 9.4, \mathrm{E}$ rosette $21.1 \% \pm 6.1$, $\mathrm{IgG} 810 \pm 241$, IgA $140.5 \pm 85$, and IgM $176.2 \pm 70 \mathrm{mg} / \mathrm{dl}$ concentrations in $\mathrm{GH}$-deficient children were comparable to age adjusted values in normal children (15). There was a gradual increase in the PHA-stimulated lymphoproliferative response which reached a significant level 9-12 months posttherapy, 123.2 \pm 51.9 versus $74.1 \pm 37.6, p<0.05$. T and $\mathrm{B}$ rosettes and immunoglobulin concentrations were not affected by GH therapy (Table 1). Delayed hypersensitivity skin tests to PPD, dermatophyton, and mumps remained unchanged. SK-SD responses converted from negative to positive in two children, and the magnitude of response changed in two others; results remained unchanged in the rest.

\section{DISCUSSION}

In vivo and in vitro studies in the pituitary dwarf mouse and the neonatally thymectomized mouse have demonstrated a direct and specific pituitary-thymic relationship $(3,11)$. In the pituitary dwarf mouse after weaning, lymphopenia develops and the thymus and peripheral lymphoid tissue progressively involute. Administration of GH increases the weight of lymphoid tissue, restores antibody responsiveness, and enables the dwarf mouse to reject allografts (6). The anterior pituitary of the neonatally thymectomized mouse on the other hand, contains enlarged degranulated acidophilic cells suggesting a feedback control of thymus on the pituitary (4). In vitro, the presence of $\mathrm{GH}$ is necessary for the generation of cytotoxic lymphocytes (13), and specific saturable GH receptors have been identified on the surface of thymocytes (2).

Although an association of immunodeficiency and shortlimbed dwarfism, without GH deficiency, has been described (1), an unusual susceptibility to or increased incidence of infections has not been observed in GH-deficient children.

In ataxia teleangiectasia certain endocrine deficiencies may be present. However, GH deficiency has not been implicated. Fleisher et al. (8) described a family with four affected members who presented with isolated GH deficiency and hypogammaglobulinemia. Three of the affected members studied prior to GH therapy had no detectable B lymphocytes in peripheral blood. In the fourth case treated with GH for $2 \mathrm{yr}, 1$ to $3 \%$ of the peripheral lymphocytes were identified as B lymphocytes and the serum IgA and IgM levels were normal. The authors raise the possibility of a GH effect on this patient's immunological system. Follow-up studies are not available on the two cases who were diagnosed at a young age and studied prior to GH therapy. 
Children with GH deficiency investigated in this study experienced no unusual susceptibility to bacterial or viral agents and their baseline immunological functions were intact. Following an extended period of GH therapy, no significant changes occurred in the immunological parameters tested. The increase in PHA-stimulated lymphoproliferative response observed following therapy is attributable to a tissue specific nuclear effect of $\mathrm{GH}$ on lymphoid cells (5).

We considered the possibility that our inability to demonstrate a pronounced $\mathrm{GH}$ effect might be related to the lack of absolute GH deficiency in these children. In addition, in those suffering from acquired GH deficiency, immune competency may not regress, as is the case in neonatally hypophysectomized mouse. Eight of the nine children studied demonstrated some GH response, albeit minimal, to various GH stimuli. Therefore, absolute GH deficiency did not exist. In one child with congenital pituitary hypoplasia and no detectable $\mathrm{GH}$ at the time of testing, the PHA stimulation response index was low (28), and markedly increased (to 204), 3 months following GH therapy. In this particular case, however, $\mathrm{T}$ and $\mathrm{B}$ lymphocytes, immunoglobulin concentrations and hypersensitivity skin tests all were normal.

The GH treatment regimen employed in this study does not restore serum GH concentrations to physiological levels. The intermittent therapy, however, has been effective in promoting growth and in generation of insulin-like growth factors dependent on the biological action of GH. Our inability to demonstrate a measured response in the several immune parameters studied may be attributable to the normal baseline immunological parameters observed in these children prior to $\mathrm{GH}$ therapy.

In summary, immunological function in children with $\mathrm{GH}$ deficiency appears intact as evidenced clinically by a lack of undue susceptibility to infectious agents, and immunologically, by normal values of various immune parameters. GH therapy does not lead to any detectable alterations in humoral or cellular immunity. An investigation of the effect of $\mathrm{GH}$ on subpopulations of lymphocytes would be of interest. However, at the time our study was conducted these techniques were not available in our laboratory.
Acknowledgment. GH was kindly provided by Dr. Salvatore Raiti, Director National Hormone and Pituitary Program, National Institute of Arthritis, Diabetes and Digestive and Kidney Diseases.

\section{REFERENCES}

1. Ammann AJ, Sutliff W, Millinchick E 1974 Antibody mediated immunodeficiency in short limbed dwarfism. J Pediatr 84:200-203

2. Arrenbrecht $S 1974$ Specific binding of growth hormone to thymocytes. Nature 525:255-257

3. Baroni C 1967 Thymus, peripheral lymphoid tissues and immunological responsiveness of the pituitary dwarf mouse. Experientia 23:282-283

4. Bianchi E, Pierpaoli W, Sorkin E 1971 Cytological changes in the mouse anterior pituitary after neonatal thymectomy: a light and electron microscopic study. J Endocrinol 51:1-6

5. Desai LS, Lazarus H, Li CH, Foley GE 1973 Human leukemic cells: Effect of human growth hormone. Exp Cell Res 81:330-332

6. Duquesnoy RJ 1972 Immunodeficiency of the thymus-dependent system of the Ames dwarf mouse. J Immunol 108:1578-1590

7. Fahey JL, McKelvey EM 1965 Quantitative determination of serum immunoglobulin in antibody-Agar plates. J Immunol 94:84-90

8. Fleisher TA, White RM, Broder S, Nissley SP, Blaese RM, Mulvihill JJ, Olive G, Waldmann TA $1980 \mathrm{X}$ linked hypogammaglobulinemia and isolated growth hormone deficiency. N Engl J Med 302:1429-1434

9. Jondal M, Holm G, Wigzell H 1972 Surface markers of human T and B lymphocytes. I-A large population of lymphocytes forming non-immune rosettes with sheep blood cells. J Exp Med 136:207-215

10. Oppenheim JJ, Schechter B 1980 Lymphocytes transformation, In: Rose NR Friedman $\mathrm{H}$ (eds) Manual of Clinical Immunology, 2nd ed. American Society of Microbiology, Washington, D.C., pp 233-245

11. Pierpaoli W, Sorkin E 1967 Cellular modification in the hypophysis of neonatally thymectomized mice. Br J Exp Pathol 40:627-631

12. Schalch DS, Parker ML 1964 A sensitive double antibody immunoassay for human growth hormone in plasma. Nature 203:1141-1142

13. Snow EC, Feldbush TL, Oaks JA 1981 The effects of growth hormone and insulin upon MLC responses and the generation of cytoxic lymphocytes. $J$ Immunol 126:161-164

14. Sorkin E, Pierpaoli W, Fabris N, Bianchi E 1972 Relation of growth hormone to thymus and the immune response. In: Pecile EA, Mueller EE (eds) Growth and Growth Hormone. Excerta Medica, Amsterdam, pp 132-142

15. Stiehm ER, Fudenberg HH 1966 Serum levels of immune globulins in health and disease: A survey. Pediatrics 37:715-727

16. Wybran J, Carr MC, Fudenberg HH 1972 The human rosette forming cell as a marker of a population of thymus-derived cells. J Clin Invest 51:25372543 